Article

\title{
Revenue Sharing in Major League Baseball: The Moments That Meant so Much
}

\author{
Duane Rockerbie ${ }^{1, *(1)}$ and Stephen Easton ${ }^{2}$ \\ 1 Department of Economics, University of Lethbridge, Lethbridge, AB T1K3M4, Canada \\ 2 Department of Economics, Simon Fraser University, Burnaby, BC V5A1S6, Canada; easton@sfu.ca \\ * Correspondence: rockerbie@uleth.ca; Tel.: +1-403-329-2517
}

Received: 31 May 2018; Accepted: 2 August 2018; Published: 6 August 2018

\begin{abstract}
Revenue sharing is a common league policy in professional sports leagues. Several motivations for revenue sharing have been explored in the literature, including supporting small market teams, affecting league parity, suppressing player salaries, and improving team profitability. We investigate a different motivation. Risk-averse team owners, through their commissioner, are able to increase their utility by using revenue sharing to affect higher order moments of the revenue distribution. In particular, it may reduce the variance and kurtosis, as well as affecting the skewness of the league distribution of team local revenues. We first determine the extent to which revenue sharing affects these moments in theory, then we quantify the effects on utility for Major League Baseball over the period 2002-2013. Our results suggest that revenue sharing produced significant utility gains at little cost, which enhanced the positive effects noted by other studies.
\end{abstract}

Keywords: revenue sharing; welfare; moments; risk aversion

JEL Classification: Z28

\section{Introduction}

Many papers in the sports economics literature have studied the effects of different types of revenue sharing systems on league outcomes. The majority have focused on its effects on league parity using both theoretical models (Kesenne (2000, 2015); Miller (2007); Rockerbie (2009); Szymanski (2004) and Vrooman (2009) are examples), and empirical evidence (Maxcy 2009; Rockerbie 2017). Others have focused on the effects on player salaries (Hill and Jolly 2015), while others have focused on team profitability (Easton and Rockerbie 2005; Kesenne 2007). These papers assume that the motivation for a league to adopt revenue sharing is to encourage financial stability and to minimize the credible threats of rival leagues. Financial stability is an often-used term that is addressed only indirectly by creating links between parity and profitability to financial stability. Our purpose in this paper is to investigate the effects of revenue sharing on financial stability more directly by considering its effects on the league distribution of local revenues, and the potential benefits (and costs) that they generate for team owners. Specifically, we show that a straight pool revenue sharing system affects the variance, skewness, and kurtosis of the league revenue distribution in a systematic but non-linear fashion. We then quantify the gains to a representative team owner by assuming a risk-averse league commissioner whose objective is to reduce financial uncertainty for team owners. Our results using data for Major League Baseball (MLB) suggest that the benefits to team owners can be significant, and that they provide a motivation for revenue sharing that we have not seen explored in the literature.

A growing literature has considered how trade-induced economic growth has resulted in greater income inequality (Dixit and Norman 1986; Goldberg and Pavcnik 2007), and how an income tax system can redistribute income to enhance the potential gains from free trade and integration. Revenue 
sharing is essentially a tax system to redistribute revenues from rich to poor teams in professional sports leagues. We focus on the sharing of local revenues in this paper. However, sharing of marketing, media, and television revenues has become a standard practice as well. The National League of MLB adopted gate revenue sharing in 1876 and the American League in 1903 (fixed dollar amounts per home ticket sold). ${ }^{1}$ The National Hockey League (NHL) adopted a limited gate revenue sharing plan in 1925 (3.5\% of home gate receipts) ${ }^{2}$ and the National Football League (NFL) a much more extensive gate sharing plan in 1960 (40\% of home gate receipts). ${ }^{3}$ Early in their histories, leagues often adopted revenue sharing during periods of rapid expansion that created a large imbalance in league revenues. Maintaining the financial stability of the league was important to ensure that teams had opponents to play games against and to stave off the threat of rival leagues. ${ }^{4}$ Today's revenue sharing plans are complex and extensive and are agreed to with players in their collective bargaining agreements. Virtually all local revenues are shared to some extent, including the local television network and cable revenues.

The long-standing gate sharing plan was used in both the National League and the American League up to the 1995 season. The 1996-2001 seasons saw MLB experimenting with different hybrid plans in each season. It was not until the 2002 season that MLB adopted the simple straight-pool revenue sharing plan that required each team to contribute $34 \%$ of its local revenue to the pool, with the pool then split up evenly among all 30 teams. ${ }^{5}$ A supplemental revenue sharing plan was established to divide up monies from the Major League Central Fund (national television rights, apparel and other rights held by Major League Baseball Properties) that were formally distributed evenly to all clubs. Each club's equal share was adjusted based on their revenue circumstance for the previous three seasons. The amount of the Central Fund to perform the adjustment was calculated to be $41.066 \%$ of the net transfer value of the straight-pool revenue sharing plan. For instance, in the last year of the agreement (2006) the net transfer value (the amount transferred from payer teams to payee teams) was approximately $\$ 1.62$ billion, giving the size of the Central Fund to be shared at $\$ 665.3$ million. To qualify to receive monies from this shared portion of the Central Fund, a club had to be a net payee in the straight-pool plan for the same season and had to have a mean local revenue for the preceding three seasons that was less than the mean local revenue for the league. The equal share for a payee was then topped up by multiplying size of the fund (\$665.3 million in 2006) by a ratio, comprised of the difference in the league mean local revenue for the previous three seasons, and the recipient's mean local revenue for the previous three seasons, divided by the sum of these differences of all recipient teams in the last three seasons. All MLB teams received monies from the Central Fund; however, high revenue teams received less than low revenue teams.

The 2007 Collective Bargaining Agreement (CBA) saw the contribution rate drop to $31 \%$ in the straight-pool revenue sharing plan of local revenues, and a new supplemental pool plan. ${ }^{6}$ The supplemental pool contained enough revenue, taken from the Major League Central Fund, to top up the total revenue sharing pool to $48 \%$ of local revenues (or roughly $17 \%$ of total local revenues amounting to $\$ 967.3$ million in the last year of the agreement (2011)) and this was distributed to teams based on performance factors that reflected the size of local television and media markets. Large market teams carried negative performance factors, while small market teams carried positive

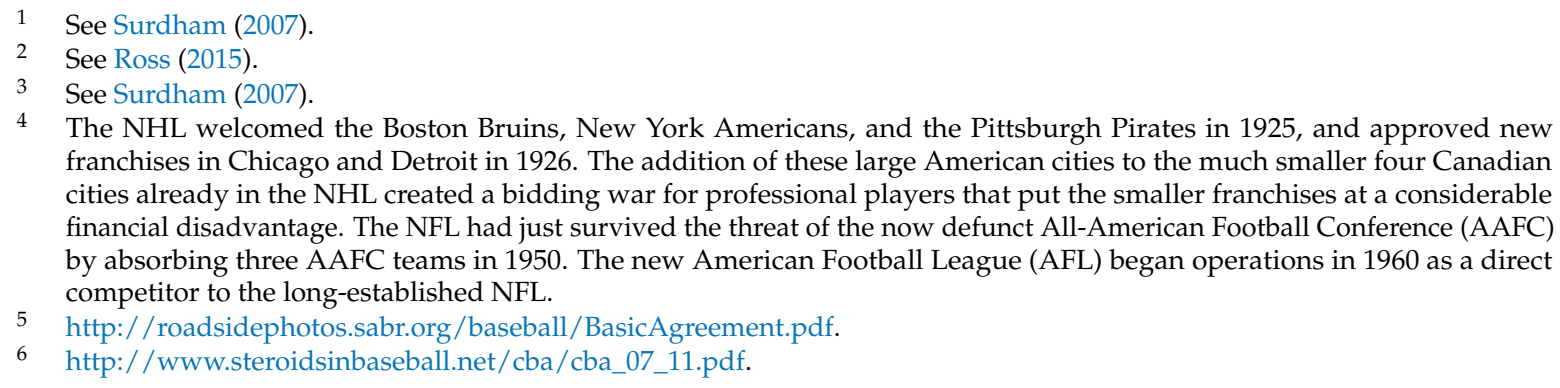


performance factors (the sum of the performance factors being zero). These monies were then added to the equal shares received from the Central Fund to calculate a net among the amount received. Again, all teams received monies from the Central Fund, but large market teams received less than small market teams.

The contribution rate was increased to $34 \%$ in the 2012 CBA, while the basic form of the supplemental pool from the Central Fund was maintained from the 2007 CBA.

We did not model the supplemental revenue sharing pool in the rest of the paper due to its asymmetric effects on team revenues, and the fact that the plan changed significantly from the 2002-2006 to the 2007-2011 CBA's. Incorporating the plan into an algebraic model to predict the effects on the league total revenue distribution proved difficult, despite our efforts. Instead we chose to focus only on the straight-pool revenue sharing plan and its effects on the moments of the league local revenue distribution. This was a shortcoming of our approach; however, we leave the problem of the distribution of the Central Fund revenues to further research.

Theoretical models have focused mainly on the effects on parity and team profitability in levels. However, it is uncertain as to how a movement towards or away from parity in winning percentages affects the stability of league revenues. We considered the effects of revenue sharing on the league distribution of team revenues in terms of its second (variance), third (skewness), and fourth moments (kurtosis). Figures 1 and 2 plot the histograms and reports the relevant moments of local revenue for the 2002 and 2011 MLB seasons. The variance of local team revenue (excluding national media, apparel, and other rights revenues shared by all teams) after revenue sharing $\left(\sigma_{A}^{2}\right)$ was less than half $(43.5 \%$ and $46.7 \%$ ) of the variance of local team revenue before revenue sharing $\left(\sigma^{2}\right)$ in each respective season, and the third (29\%) and fourth (19\%) moments were also reduced. The biggest contributor to the revenue sharing plan in both seasons was the New York Yankees, contributing a net sum of approximately $\$ 52$ million in 2002 and \$100 million in 2011. The Yankees owners (G. and H. Steinbrenner) could not have been happy with making a net contribution of $\$ 754$ million over the 2002 to 2011 seasons; however, the Yankees carry only one vote when it comes to changing league policy. Although it is a net zero gain to the league in terms of total and average local revenue, the reduction in risk alone that revenue sharing provided must have been greatly valued by a majority of other owners.

Reducing its variance has obvious benefits with risk-averse team owners, but reducing its third and fourth moments ${ }^{7}$ has a more complex effect on benefits. ${ }^{8}$ Reducing skewness implies a more equal distribution of team revenues-a desirable result for a league composed of socialist owners, but team owners are capitalists who prefer more rather than less, and their commissioner is chosen to represent their financial interests. As we shall show, a league with a higher positive skewness has a lower likelihood of downside risk, and is preferred by the representative team owner. While it is not the worst outcome, equality of team revenues is preferred to a higher downside risk $\left(\sigma^{3}<0\right)$.

7 We refer to the average cubed deviation around the mean as $\sigma^{3}$ as it is clearly related to the idea of skewness. It is not the coefficient of skewness. The Pearson definition of skewness is $n^{-1} \sum\left(\left(R_{i}^{A}-\bar{R}\right) / \sigma\right)^{3}$; however, we refer to $\sigma^{3}$ as a characterization of skewness in the rest of the paper.

8 The third moment is characterized as being associated with "prudence" (Kimball 1990), and the fourth moment as being associated with "temperance" (Eeckhoudt et al. 1995). See Chiu (2005), or Eeckhoudt and Schlesinger (2013) for additional interpretation of these and higher order moments. 


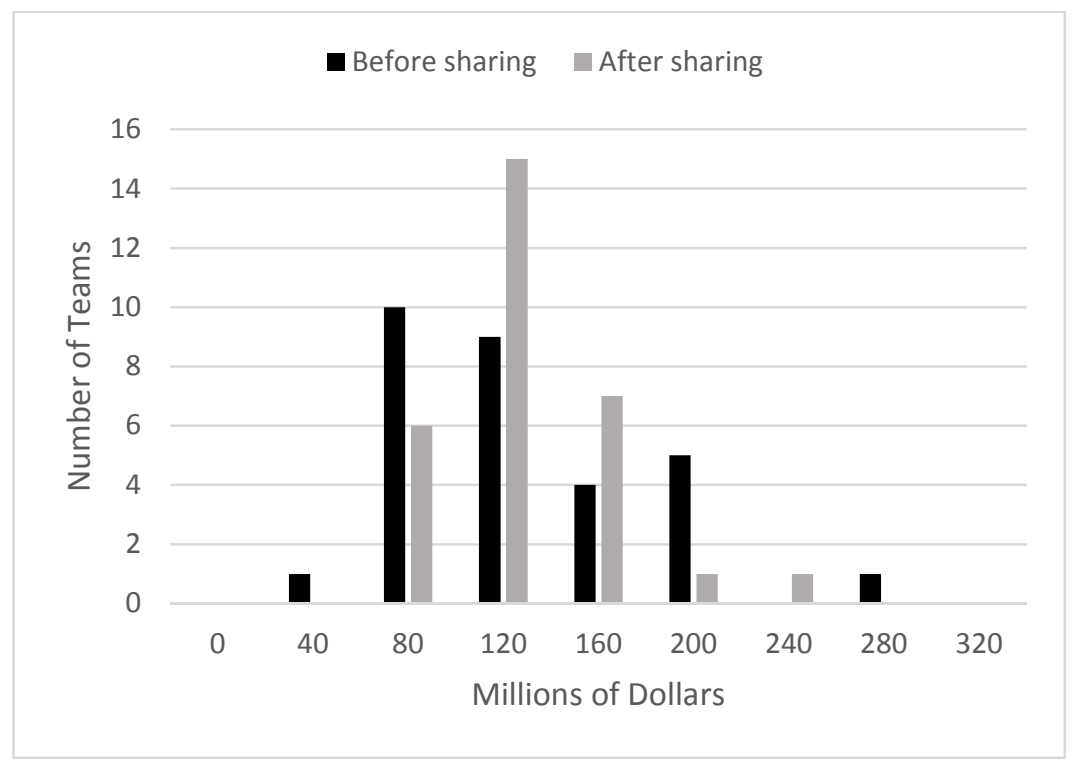

Figure 1. Local revenues pre- and post-revenue sharing in Major Baseball League (MLB), 2002 season. $\left(\bar{R}=\$ 109.4\right.$ million, $\sigma^{2}=2607.2, \sigma_{A}^{2}=1135.7, \sigma^{3}=3,720,200, \sigma_{A}^{3}=1,069,542, \sigma^{4}=24,251,058$, $\left.\sigma_{A}^{4}=4,601,574\right)$. Sources: Post-revenue sharing data taken from Rodney Fort's Sports Economics website, https://sites.google.com/site/rodswebpages/codes. Pre-revenue sharing data based on author's calculations.

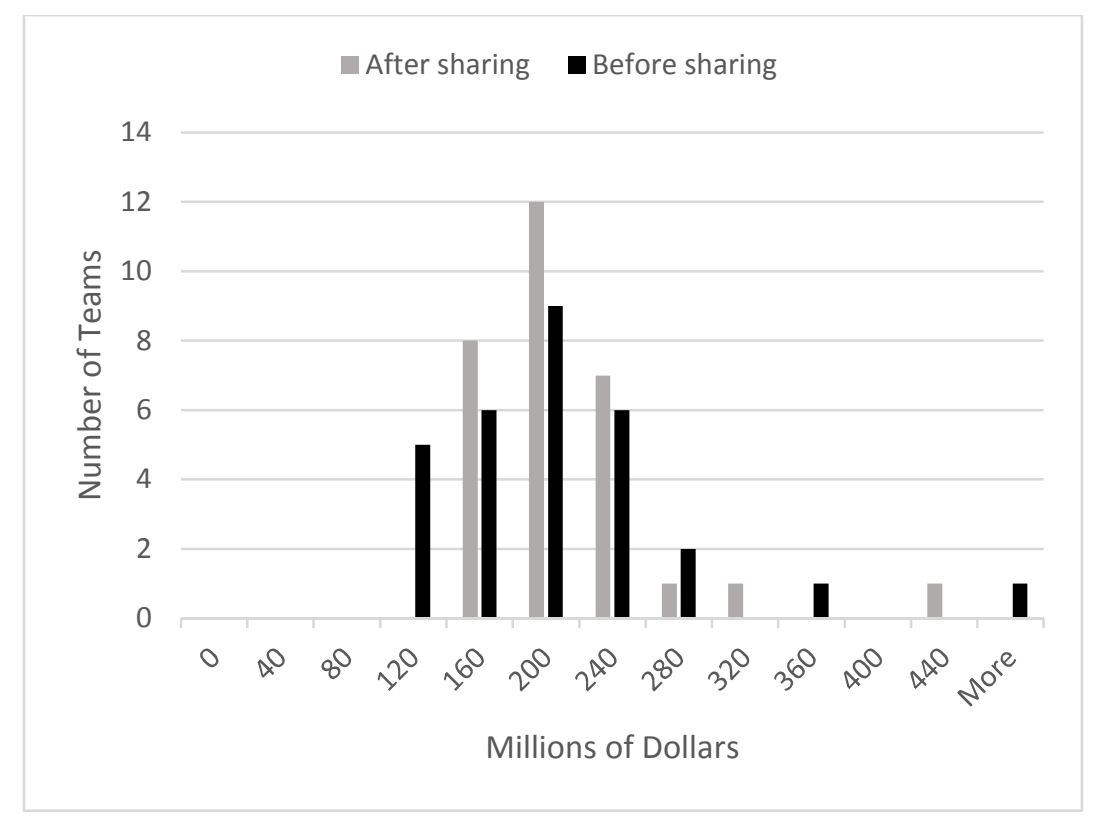

Figure 2. Local revenues pre and post-revenue sharing in MLB, 2011 season. $(\bar{R}=\$ 189.7$ million, $\left.\sigma^{2}=6234.2, \sigma_{A}^{2}=2968.1, \sigma^{3}=36,153,429, \sigma_{A}^{3}=5,053,763, \sigma^{4}=166,465,178, \sigma_{A}^{4}=93,707,469\right)$. Sources: Post-revenue sharing data taken from Rodney Fort's Sports Economics website, https:/ / sites. google.com/site/rodswebpages/codes. Pre-revenue sharing data based on author's calculations.

\section{Risk Aversion and Revenues}

To motivate the effects of revenue sharing, we will assume that team owners are risk-averse and maximize their utility from profit. This differs from the standard sports league model that assumes risk-neutral team owners who maximize profit (or winning or a combination of the two). 
Consumers are often thought of as being risk-averse when facing a gamble that will affect their income or wealth. In the simplest case of a sports league, a representative team owner faces an uncertain portion of team revenue (excluding fixed revenues that arise from the Major League Central Fund) from season to season, that takes on only two outcomes, high or low. These uncertain revenues arise from the inherent uncertainty of team performance due to injuries or changes in the performance of competing teams, or changing local market conditions. While team owners do not have the choice of accepting a certainty equivalent amount of revenue, as explained below, they may prefer league policies that reduce the variation (or higher moments) of team revenues and raise their utility.

When speaking of risk aversion in firms, the economics literature defines the owner of a firm as an "entrepreneur". The connotation is that being an entrepreneur means starting a new business that has risky/uncertain financial outcomes, instead of the faceless widget producer who faces a certain demand that is assumed in textbooks. ${ }^{9}$ Table 1 provides a summary of ownership structures in the four major North American professional sports leagues. The vast majority are partnerships (with the exception of MLB at 16 out of 30 teams) that identify as limited liability corporations (LLCs) for tax purposes ${ }^{10}$ and identify one individual as the majority owner. In fact, the NFL prohibits standard corporate ownership of its teams, with the historical exception of the Green Bay Packers, which is community-owned. Consequently, thinking about professional sports teams as having one or two investor/owners who are responsible for most business decisions is completely appropriate, given their actual ownership structures.

Table 1. Ownership structures in North American professional sports leagues, $2018 .^{11}$

\begin{tabular}{cccc}
\hline & Normal Corporation & Partnerships/LLC & Identify Majority Owner \\
\hline MLB & 14 & 16 & 28 \\
NBA & 10 & 20 & 30 \\
NHL & 6 & 25 & 30 \\
NFL & 1 & 31 & 31 \\
\hline
\end{tabular}

In the simplest case, if the firm delegates decisions to a manager whose pay is linked to firm performance, the firm may display risk-averse behavior. However, firms may display risk-aversion for several other reasons. Firms in a perfectly competitive industry may reduce output when facing demand uncertainty (Sandmo 1971); Leland (1972) demonstrates the same result for a risk-averse monopoly, while Asplund (2002) suggests that only greater cost uncertainty reduces output for a risk-averse oligopoly firm. Some empirical evidence is provided by Herranz et al. (2015) who show that risk-averse entrepreneurs run smaller, more highly leveraged firms with lower default risk. This behavior is consistent with U.S. business data for approximately 5 million small firms whose owners invest a large amount of their own wealth in the business, and typically work at the business.

\section{A League: When Monopoly Does Not Maximize Individual Profit}

Team owners are entrepreneurs who invest in costly talent that produces an uncertain outcome (wins). As Neale (1964) first noted, a professional sports firm requires other firms (teams) to produce an output (games) and earn revenue. At the local level, team owners are competitive on the field,

9 Frank Knight (1921) in Risk, Uncertainty and Profit, called attention to this reality as early as 1921.

10 The assets of owners of limited liability corporations (LLCs) are protected from creditors in the event of default of the LLC. Their corporate structure does not include a Board of Directors or Officers; instead, decisions rest with the owner(s). Any profit from the LLC is reported as taxable personal income for the owner(s) to avoid the double taxation of corporate profit and personal income received from dividends.

11 Source: https://www.baseball-reference.com/bullpen/List_of_Major_League_Baseball_principal_owners, https://en. wikipedia.org/wiki/List_of_NBA_team_owners, http://icehockey.wikia.com/wiki/List_of_NHL_Owners, https://en. wikipedia.org/wiki/List_of_NFL_franchise_owners. 
but engage in a joint venture at the league level. ${ }^{12}$ League policies that might appear to be collusive (a common set of rules, a playing schedule, a player draft, free agency, and so on) must be adopted to insure the survival of the league and, thus, each team. The fact that team owners often argue that revenue sharing is necessary for the stability of the league (Bontemps 2017) is some evidence that they are sensitive to profit risk. Revenue sharing requires the approval of a majority of team owners. For those owners who earn consistent profits, giving up some profit to insure that smaller market teams survive is a form of insurance premium for future revenue stability. Outside of a professional sports league, any movement towards a monopoly benefits the profit position for a firm, but not so for a professional sports team owner.

Risk aversion has a long tradition in the labor economics literature. Generally, risk-averse firms suffer much lower utility in the low demand state than in the high demand state; thus, they reduce their output and hire fewer workers to reduce costs and maintain profitability. Choudhary and Levine (2010) review this literature. Professional sports teams do not hire and fire homogeneous workers, but instead face fixed roster sizes. Hence, they must adjust payroll costs by increasing or reducing the stock of team talent. Krautmann (2017) found evidence to suggest that team owners demonstrate risk aversion by paying a premium to MLB players who demonstrate consistent performance. Maxcy (2004) suggested that team owners reward consistent players with longer term contracts. Consistent player performance translates into consistent team revenues, suggesting that team owners value consistent revenues that can be made even less variable with revenue sharing. ${ }^{13}$

Risk aversion has also been used to explain why workers prefer stable employment contracts that pay a lower wage in the face of uncertain productivity. Wages and employment will then appear to be somewhat inflexible during swings in productivity (business) cycles. Employers who are risk-neutral will be indifferent between such a contract and a bonus-based contract. A good reference is Thomas and Worrall (1988). This might explain why professional athletes may prefer long-term contracts with stable salaries to short-term performance-based contracts. Although this is an interesting research area, we consider the effects of revenue sharing only on team owners, admitting that risk aversion might play a role in contract negotiations and subsequent team owner utility.

Prudence, or in our case the reduction of downside risk, is a characteristic of the individual who buys insurance, and is described by the skewness of revenues. Risk aversion and prudence are not identical, but they are related (Kimball 1990; Chiu 2005). As we show below, a risk-averse team owner benefits from prudence and consequently reduces the likelihood of a bad revenue state.

To fix ideas, Eeckhoudt and Schlesinger (2013) imagine a lottery with two outcomes. In state 1, we receive $X-k$ in which $k$ is a fixed amount, and in state 2 , we receive $X+e$ where e is a mean zero random payout with finite variance. Now consider a second lottery in which the good state receives $X$ and the bad state receives $X-k+e$. Since the second lottery increases the downside risk but leaves the mean and the variance unchanged, a prudent individual is defined as one who prefers the first lottery to the second. The first lottery attaches the sure loss to the state with no risk, while in the second lottery, the sure loss is attached to the state with risk, e. This behavior means that for a given mean and variance, negative skewness in revenues is undesirable for the league.

Temperance describes a representative team owner who wishes to avoid a large probability density in both tails of the revenue distribution—avoiding extreme outcomes. This translates to a small value for the fourth moment (kurtosis) of the league revenue distribution.

12 See for example https:/ / www.lexology.com/library/detail.aspx?g=31d92fbf-9e64-4aaa-a5e4-a1f56bc23c8a.

13 We are grateful to a referee for pointing out that there is a derived demand for minor league performance leading to major league outcomes. Although we do not explore this relationship, it has been considered with dramatically different conclusions in two sources. https:/ / www.baseballamerica.com/stories/ quantifying-the-effects-of-winning-in-the-minorleagues-on-player-development/, http:/ / washusportsanalytics.weebly.com/our-research/the-value-of-minor-leagueseasoning. 


\section{The Model}

Our sports league is composed of $n$ teams. Each team owner contributes a share $(1-\alpha)$ of its local revenue into a straight pool, which is then divided evenly among the team owners at the end of each playing season. Local revenues are obtained primarily from ticket sales, but they may also contain other local revenues that increase with the performance of the team. We ignore other types of revenue that are not typically dependent upon team performance. To focus on the static consequences of revenue sharing, we do not explicitly model the determination of the profit-maximizing revenue for each team. We acknowledge that revenue sharing can affect the optimal choice of talent and thus team revenue. It is an undisputed result in the theoretical literature that revenue sharing reduces the demand for talented players and subsequently lowers salaries (Fort and Quirk 1995). This is a positive benefit for team profits that we cannot model without resorting to a simultaneous equation system composed of a marginal revenue function for each team. If one could model such a complex system, the increase in team profitability due to revenue sharing could only enhance the positive effects that we demonstrate here.

The bulk of the theoretical literature on revenue sharing has come into agreement that increased revenue sharing reduces league parity (Kesenne (2000, 2015), Miller (2007), Szymanski (2004), and Vrooman (2009) that could have negative consequences for consumer welfare if fans value close contests (the uncertainty of outcome hypothesis or UOH). Fort and Quirk (2010a, 2010b) use the sum of consumer and producer surpluses to compare welfare at different levels of league parity. Dietl, Lang and Werner (Dietl et al. 2009) show that revenue sharing increases welfare measured as the sum of consumer surplus and team profits. To capture this effect in our model would require an estimation of the effects of the 2002, 2007, and 2012 changes to the straight-pool revenue sharing plan on league parity, and an assumption of some sort of consumer welfare function that values the $\mathrm{UOH}$. Instead we have chosen to focus on the isolated effect of revenue sharing on the moments of the league distribution of revenues. We acknowledge this as a shortcoming of our approach and leave it to further research to investigate the salary and parity effects of revenue sharing on total league and consumer welfare.

Revenue for team $i$ after revenue sharing (where an " $A$ " distinguishes revenue after sharing) is given by:

$$
R_{i}^{A}=\alpha R_{i}+(1-\alpha) \sum R_{j} / n=\alpha R_{i}+(1-\alpha) \bar{R}
$$

In (1), $\bar{R}=\sum_{j=1}^{n} R_{j} / n$, the average team local revenue for the league before revenue sharing. ${ }^{14}$ We need not consider the theoretical result that revenue sharing reduces the incentive of team owners to acquire talent and earn revenue, since we are not solving a team owner maximization problem. Instead we accept that each $R_{j}$ has been determined ex-post by the profit maximizing decision of the owner of team $j$, accounting for the revenue sharing payments that each will contribute or receive.

Utility is representative of any one of the owners (a representative agent model) and is calculated as a constant relative risk aversion utility function of the form ${ }^{15}$ :

$$
U=R^{1-\theta} / 1-\theta
$$

The $\theta$ term is the coefficient of relative risk aversion and $R$ is the local revenue of a representative team owner. Revenue sharing affects the league distribution of revenues, and we focus our analysis on the utility effects for the resulting representative owner.

14 It is easy to show that the average local revenue is unchanged by revenue sharing. Using (1), $\bar{R}^{A}=\sum R_{j}^{A} / n=$ $\left(\sum \alpha R_{j}+\sum(1-\alpha) \bar{R}\right) / n=\alpha \bar{R}+(1-\alpha) \bar{R}=\bar{R}$.

15 The CRRA utility function is a popular choice in models of consumption and real business cycles for two reasons: risk aversion is invariant to the level of consumption, income and wealth; utility is stationary, that is, moving the same consumption path forward one or more periods does not change the preference ordering of goods to consume. See Lucas (1987). 
We utilize a Taylor series expansion of a representative owner's CRRA utility function as an approximation to the utility obtained from an expected utility maximization problem. This is the approach pioneered by Markowitz (1952) to develop his mean-variance portfolio model, although he only considered the first two moments of the return distribution. Kraus and Litzenberger (1976) extend the CAPM analysis to the third moment. This approach is not without controversy. Loistl (1976) demonstrated that a Taylor series expansion does not approximate the portfolio results of expected utility maximization very well, except for the case of a quadratic utility function. However, a number of papers have suggested that the degree of error is very slight, by the use of simulations of different choice models (Levy and Markowitz (1979), Pulley (1981), Kroll et al. (1984), Tew et al. (1991), and Tompkins (2000) are a few), typically on the order of $\$ 0.00025$ per dollar invested. In addition, their results suggest that the error decreases with the number of assets in the portfolio; in our case, teams sharing the revenue in the league. In our case, the Taylor series approximation adds the ease of measurement of utility, as well as bringing in the first four moments of the league revenue distribution into the discussion in a coherent way.

To approximate utility for the representative owner and to introduce the first four moments of the league revenue distribution, we take a Taylor series expansion of (2) around the average team local revenue, limited to the first four terms. ${ }^{16}$

$$
\begin{gathered}
U \approx \frac{\bar{R}^{1-\theta}}{1-\theta}+\bar{R}^{-\theta}(R-\bar{R})-\frac{\theta}{2} \bar{R}^{-\theta-1}(R-\bar{R})^{2}+\frac{\theta(\theta-1)}{3 !} \bar{R}^{-\theta-2}(R-\bar{R})^{3} \\
-\frac{\theta(\theta-1)(\theta-2)}{4 !} \bar{R}^{-\theta-3}(R-\bar{R})^{4}
\end{gathered}
$$

Before revenue sharing in any season, local revenue for the representative owner can deviate from its mean due to shocks that we specify as $R=\bar{R}+e$ without specifying the nature of these shocks, and assuming $E(e)=0$ and $\operatorname{Var}(e)=\sigma^{2}$. The average local revenue is unchanged after revenue sharing, hence the second term in (3) vanishes after taking its expected value, while the variance and skewness and kurtosis of local revenue after revenue sharing are denoted as:

$$
\begin{aligned}
& E\left(R_{i}^{A}-\bar{R}\right)^{2}=\sigma_{A}^{2}=\frac{1}{n} \sum\left(R_{i}^{A}-\bar{R}\right)^{2} \\
& E\left(R_{i}^{A}-\bar{R}\right)^{3}=\sigma_{A}^{3}=\frac{1}{n} \sum\left(R_{i}^{A}-\bar{R}\right)^{3} \\
& E\left(R_{i}^{A}-\bar{R}\right)^{4}=\sigma_{A}^{4}=\frac{1}{n} \sum\left(R_{i}^{A}-\bar{R}\right)^{4}
\end{aligned}
$$

Thus:

$$
\begin{gathered}
E(U)=\left[R^{1-\theta} / 1-\theta\right]-\frac{\theta}{2} \bar{R}^{-(1+\theta)} \sigma_{A}^{2}+\frac{\theta(\theta-1)}{6} \bar{R}^{-(2+\theta)} \sigma_{A}^{3} \\
-\frac{\theta(\theta-1)(\theta-2)}{4 !} \bar{R}^{-(3+\theta)} \sigma_{A}^{4}
\end{gathered}
$$

\subsection{Risk Aversion}

Risk aversion suggests that greater variability in team revenue $\left(\sigma_{A}^{2}\right)$ reduces utility. Risk-averse team owners seek to reduce the variability in revenues by diversifying their revenue "portfolios", and revenue sharing provides a mechanism to do this, although we do not pursue this team-specific

16 Lucas (1987) used the same expansion method to evaluate the welfare gain from consumption smoothing. He did not expand to the fourth term in (3), since he did not have the data necessary to compute the moments of the distribution of U.S. aggregate consumption. 
portfolio effect. ${ }^{17}$ Rather, we assume that the representative team owner is concerned with the variance and higher orders of the distribution of team local revenues around the team average.

\subsection{Skewness Reflects Prudence}

The effect of skewness on utility depends upon the degree of relative risk aversion. If the representative owner is risk-averse and we assume $\theta>1$, positive skewness in revenues $\left(\sigma_{A}^{3}>0\right)$ will increase expected utility. ${ }^{18}$ Positive skewness will reduce the likelihood that poor revenue for one or more teams will threaten the stability of the league. Revenue sharing is a policy that will also contribute to stability. Prudent owners will benefit from skewness. It is important not to confuse skewness in revenues with a lack of revenue equity that some might associate with lower welfare. In our model, the league wishes to see the majority of teams doing well on the revenue side. How revenue sharing affects skewness is specifically addressed in a later section; however, any improvement in revenue equity, as measured by a movement to a more symmetric league revenue distribution from positive skewness, will lower league utility.

To see each of the effects of the variance, skewness and kurtosis on utility, we consider each individually before amalgamating.

\subsection{Revenue Sharing and the Variance of Team Revenues}

To calculate the variance of team revenues after revenue sharing, one might be tempted to use the simple rule of variances that $\operatorname{Var} a X=a^{2} \operatorname{Var} X$, since part of the local revenue after sharing is just $\alpha R_{i}$, but this would ignore the payment received from the revenue-sharing pool. The variance of team revenues around the league average after revenue sharing is not as obvious as the simple rule, but it is not hard to derive:

$$
\sigma_{A}^{2}=E\left(R_{j}^{A}-\bar{R}\right)^{2}=\frac{1}{n} \sum_{j=1}^{n}\left(R_{j}^{A}-\bar{R}\right)^{2}
$$

Consider the bracketed term only for team $i$ and insert (1):

$$
\left(R_{i}^{A}-\bar{R}\right)^{2}=\left(\alpha R_{i}+(1-\alpha) \bar{R}-\bar{R}\right)^{2}=\left(\alpha\left(R_{i}-\bar{R}\right)\right)^{2}=\alpha^{2}\left(R_{i}-\bar{R}\right)^{2}
$$

Each of the $\mathrm{n}$ teams will have the same expression as (6), with the terms inside the brackets using values for the individual team. Summing over the $n$ teams gives:

$$
\sigma_{A}^{2}=\frac{1}{n} \sum_{j=1}^{n}\left(R_{j}^{A}-\bar{R}\right)^{2}=\alpha^{2} \frac{1}{n} \sum_{j=1}^{n}\left(R_{j}-\bar{R}\right)^{2}=\alpha^{2} \sigma^{2}
$$

The reduction in the variance of league revenues after revenue sharing is proportional to $\alpha^{2}$. If we think of the variance of local revenues as a measure of risk, revenue sharing reduces this risk by a factor of $0.69^{2}=0.4761$ in MLB ( $\alpha=0.69$ as per the 2016 CBA), which is a 31 percent reduction from no revenue sharing.

17 Revenue sharing in the form assumed in this paper allows team owners to diversify their revenue portfolios by essentially investing in the economic health of other teams. Two requirements are necessary for team owners to benefit from a portfolio effect. First, team revenues should display some sort of cyclical behavior; second, and related to the first requirement, a majority of teams should display a negative covariance with the revenues of other teams or the league average revenue. Most professional sports teams have periods of strong revenue growth, followed by periods of revenue stagnation or decline. The cyclical nature of winning percentages and a possible cause of this has been explored by Easton and Rockerbie (2010), and Rockerbie and Easton (2014). Revenues are at least partially determined by success on the field, however the cyclical nature of team revenues has not been deeply explored in the literature. The majority of team owners that vote in favor of revenue sharing might do so if they perceive a benefit from the portfolio effect, implying that their local revenue displays a negative covariance with the local revenues of other teams.

18 Below, we will argue for $\theta>3$. In the special case of $\theta=1$, we have a log utility function, and skewness does not affect the utility, from inspection of (4). 
Risk-averse team owners will value the reduction in risk that revenue sharing delivers. But by how much? The relevant part of (4) is $-\frac{\theta}{2} \bar{R}^{-(1+\theta)} \sigma_{A}^{2}$. Consider the one-shot adoption of revenue sharing that reduces $\alpha=1$ to $\alpha=0.69$. Expressing the increase in utility relative to marginal utility $\left(\bar{R}^{-\theta}\right.$ when evaluated at the mean) gives the increase in dollars per unit of utility. Next, dividing by the average local revenue for the league $(\bar{R})$ expresses the welfare change as a percentage of average league revenue ${ }^{19}$ :

$$
\frac{\Delta U / U^{\prime}}{\bar{R}}=-\frac{(\theta / 2) \bar{R}^{-(1+\theta)}\left(\sigma_{A}^{2}-\sigma^{2}\right)}{\bar{R}^{-\theta} \bar{R}}=-\frac{\theta\left(\alpha^{2}-1\right) \sigma^{2}}{2 \bar{R}^{2}}=\left(\frac{\theta}{2 \bar{R}^{2}}\right) 0.5239 \sigma^{2}>0
$$

The larger the variance in league local revenues before revenue sharing, the larger the welfare gains are from revenue sharing, and the larger is the average local revenue of the league, the smaller are the utility gains from revenue sharing. Leagues composed of very wealthy teams playing in large markets may stand little to gain in utility by instituting revenue sharing.

\subsection{Revenue Sharing and the Skewness of League Revenues}

Skewness is also important to the utility of the representative. Positive skewness provides higher utility because it indicates a low probability of a poor revenue outcome for one or more of the teams. Skewness after revenue sharing is defined as:

$$
\sigma_{A}^{3}=E\left(R_{j}^{A}-\bar{R}\right)^{3}=\frac{1}{n} \sum_{j=1}^{n}\left(R_{j}^{A}-\bar{R}\right)^{3}
$$

Using the same method used to derive the variance, the skewness in local revenues is given by:

$$
\sigma_{A}^{3}=\alpha^{3} \sigma^{3}
$$

The reduction in skewness of the league revenue distribution that revenue sharing delivers is proportional to $\alpha^{3}$. For MLB, this is $0.69^{3}=0.3285$, again a significant reduction, but in this case, a reduction in utility for the league if the league revenue distribution is positively skewed. How much will the league (representative owner) value the reduction in skewness with greater revenue sharing? The relevant part of (4) is $\frac{\theta(\theta-1)}{6} \bar{R}^{-(2+\theta)} \sigma_{A}^{3}$. Again, expressing the increase in utility relative to marginal utility, and then expressing it as a percentage of average league revenue gives the results of a decrease in welfare for the league by increasing revenue sharing:

$$
\frac{\Delta U / U^{\prime}}{\bar{R}}=\frac{\theta(\theta-1)}{6 \bar{R}^{3}} \sigma^{3}\left(0.69^{3}-1\right)=-\frac{\theta(\theta-1)}{6 \bar{R}^{3}} 0.6715 \sigma^{3}<0
$$

\subsection{Revenue Sharing and the Kurtosis of League Revenues}

Positive kurtosis indicates that the league revenue distribution has "heavy tails", or that there is a significant probability of extreme revenue results. This reduces the utility for the representative owner from the last term in (4). Kurtosis after revenue sharing is defined as:

$$
\sigma_{A}^{4}=E\left(R_{j}^{A}-\bar{R}\right)^{4}=\frac{1}{n} \sum_{j=1}^{n}\left(R_{j}^{A}-\bar{R}\right)^{4}
$$

19 The average revenue for the representative owner is the same as the average league revenue across all teams. 
Using the same method used to derive the variance, the kurtosis in local revenues is given by:

$$
\sigma_{A}^{4}=\alpha^{4} \sigma^{4}
$$

The reduction in kurtosis of the league revenue distribution that revenue sharing delivers is proportional to $\alpha^{4}$. A representative owner that displays temperance, values the reduction in kurtosis as provided by revenue sharing, by the amount $-\frac{\theta(\theta-1)(\theta-2)}{4 !} \bar{R}^{-(3+\theta)} \sigma_{A}^{4}$ from (4). Here, we are also assuming that $\theta>2$. Expressing the utility gain as a percentage of the average team revenue gives:

$$
\frac{\Delta U / U^{\prime}}{\bar{R}}=\frac{\theta(\theta-1)(\theta-2)}{24 \bar{R}^{4}} \sigma^{4}\left(0.69^{4}-1\right)=\frac{\theta(\theta-1)(\theta-2)}{24 \sigma^{4}} 0.7733 \sigma^{4}>0
$$

\section{Overall Utility Gains from Revenue Sharing}

Revenue sharing increases the utility for the representative owner by reducing the variance of local revenues around the league average and reducing kurtosis, but lowers the utility by reducing positive skewness. However, if skewness were to be negative, then revenue sharing would raise utility. The net change in utility is the sum of (8), (11), and (14).

$$
\text { Net } \frac{\Delta U / U^{\prime}}{\bar{R}}=-\frac{\theta\left(\alpha^{2}-1\right) \sigma^{2}}{2 \bar{R}^{2}}+\frac{\theta(\theta-1)\left(\alpha^{3}-1\right) \sigma^{3}}{6 \bar{R}^{3}}-\frac{\theta(\theta-1)(\theta-2)\left(\alpha^{4}-1\right) \sigma^{4}}{24 \bar{R}^{4}}
$$

The measurement of the utility gain in (15) requires the accurate data concerning the distribution of team revenues to be meaningful. Professional sports leagues do not make these data publicly available. We require local revenues before revenue sharing for every team in a professional sports league. MLB released accurate data for the 1995 through 2001 seasons in a supplement to its Blue Ribbon report (Major League Baseball 2001). Team local revenues before revenue sharing are reported in Table 2 of the report. ${ }^{20}$ Unfortunately MLB did not use the straight-pool revenue sharing plan that we assumed, in deriving Equations (7), (10), and (13) in any of these seasons. The Blue Ribbon report provided a unique glimpse into the financial numbers for MLB. ${ }^{21}$ As much as we would like to use data from the report, we cannot for two reasons. First, as already noted, the derivations of Equations (7), (10), and (13) that determine the properties of straight-pool revenue sharing on the variance and skewness of the league revenue distribution do not hold for the forms of revenue sharing used in the 1995-2001 seasons. Second, team owners form expectations of the amount of revenue to be contributed to the revenue sharing pool when making their talent acquisitions, setting ticket prices, and other financial decisions. These decisions incorporate the pre-revenue sharing local revenue figures. Using local revenue data for different revenue sharing plans is not consistent with team owner expectations.

Forbes magazine publishes estimates of gate revenue before revenue sharing for MLB, beginning in 1990. We have chosen the 2002-2013 MLB seasons, since the straight-pool revenue sharing plan was used in each season. Forbes reports the estimates of gate revenue, other revenue, and total revenue. ${ }^{22}$ Other revenue includes all other sources of local revenue (parking, concessions, marketing, local media,

20 Local revenue consists of gate receipts, local television, radio and cable rights fees, ballpark concessions, local advertising, sponsorship and publications, parking, suite rentals, and postseason and spring training revenues. Local revenues are the largest single component of most clubs' total annual revenues. The only other significant source of revenue is the Major League Central Fund revenue that is not distributed from the supplemental revenue sharing plan. See footnote 21.

21 Financial statements for MLB clubs are sometimes leaked by the press or presented voluntarily by MLB clubs, but only sporadically. See Rod Fort's website for limited data for the Seattle Mariners, Milwaukee Brewers, and Cleveland Indians (https://sites.google.com/site/rodswebpages/codes). More recent data for the Los Angeles Angels, Florida Marlins, and Pittsburgh Pirates can be found at http:/ / deadspin.com/5615096/mlb-confidential-the-financial-documents-baseballdoesnt-want-you-to-see-part- 1 .

22 The data are conveniently located at Rod Fort's website, https://sites.google.com/site/rodswebpages/codes. 
and so on), as well as the net revenue sharing payment received and the share of the national broadcast revenue. To evaluate Equation (15), we require total local revenue before revenue sharing. We first subtract the share of the national television broadcast revenue from the reported total local revenue ${ }^{23}$ that is not shared through the supplemental revenue sharing plan. All the remaining local revenue is shared and is reported net of any revenue sharing payment. We calculate local revenue before sharing using the formula $R_{1}=\left(R_{1}^{A}-(1-a) \bar{R}\right) / \alpha$ using the values $\alpha=0.66, \alpha=0.69$, and $\alpha=0.66, \alpha=0.69$, and $\alpha=0.66$ for the 2002-2006, 2007-2011, and 2012-2013 periods respectively. Finally, we divided by the national consumer price index $(2002=100)$ to convert to real local revenues. ${ }^{24}$

In our Table 2, we estimated the utility gains to MLB in the 2002-2013. We use the parameter values $\alpha=0.66$ (2002-2006), $\alpha=0.69$ (2007-2011), $\alpha=0.66$ (2012-2013) and $\theta=3$. Our choice of value for $\theta$ is based on survey evidence found in Mehra and Prescott (1985); however, using $\theta=2$ eliminates any utility gains from temperance, and using $\theta=1$ eliminates any gains from skewness, so we chose $\theta=3$ to include all of the utility gains. The utility gain due to the decrease in the variance of team revenues ranged from $9.5 \%$ to $18.4 \%$, averaging $14.1 \%$ of the average team revenue, over and above what the change would have been without revenue sharing. The losses due to reducing positive skewness were modest, ranging from $-3.8 \%$ to $-22.5 \%$, averaging $-9.4 \%$. This utility-reducing effect of revenue sharing was evident in all of the 2002-2013 seasons.

Table 2. Average utility gains per team in MLB, 2002-2013 seasons. $(\alpha=0.66(2002-2006), \alpha=0.69$ (2007-2011), $\alpha=0.66$ (2012-2013), $\theta=3$ ).

\begin{tabular}{|c|c|c|c|c|c|c|c|c|c|}
\hline Season & $\bar{R}$ (\$millions) & $\sigma^{2}$ & $\sigma^{3}$ & $\sigma^{4}$ & $\begin{array}{c}\text { Utility } \\
\text { Gain from } \\
\text { Variance }^{1}\end{array}$ & $\begin{array}{l}\text { Utility Gain } \\
\text { from } \\
\text { Skewness }\end{array}$ & $\begin{array}{l}\text { Utility } \\
\text { Gain from } \\
\text { Kurtosis }^{1}\end{array}$ & $\begin{array}{l}\text { Total } \\
\text { Utility } \\
\text { Gain }{ }^{1}\end{array}$ & $\begin{array}{c}\text { Total Utility } \\
\text { Gain in \$ } \\
\text { Millions }\end{array}$ \\
\hline 2002 & 109.4 & 2607.2 & 124,007 & $24,251,058$ & 0.184 & -0.067 & 0.034 & 0.151 & 16.55 \\
\hline 2004 & 123.77 & 2445.9 & 162,612 & $35,292,374$ & 0.135 & -0.061 & 0.030 & 0.105 & 12.94 \\
\hline 2005 & 133.86 & 2023.4 & 129,960 & $27,444,089$ & 0.095 & -0.038 & 0.017 & 0.074 & 9.91 \\
\hline 2006 & 142.06 & 2409 & 173,012 & $36,258,488$ & 0.101 & -0.043 & 0.018 & 0.076 & 10.81 \\
\hline 2009 & 137.62 & 4696.4 & 849,723 & $255,211,618$ & 0.191 & -0.212 & 0.131 & 0.110 & 15.36 \\
\hline 2010 & 150.78 & 3858.9 & 603,760 & $169,196,801$ & 0.132 & -0.117 & 0.062 & 0.078 & 11.78 \\
\hline 2011 & 152.19 & 3995.4 & 603,327 & $166,465,178$ & 0.134 & -0.113 & 0.059 & 0.080 & 12.21 \\
\hline 2012 & 159.3 & 4370.5 & 722,975 & $203,827,486$ & 0.143 & -0.124 & 0.062 & 0.081 & 13.03 \\
\hline 2013 & 161.1 & 4717.7 & 559,595 & $147,568,889$ & 0.145 & -0.087 & 0.039 & 0.097 & 16.12 \\
\hline
\end{tabular}

Our model suggests that revenue sharing should reduce any leptokurtic characteristic (kurtosis) of the league revenue distribution. From Table 2, the utility gain ranged from $1.7 \%$ to $6.2 \%$ of the average annual team revenue, with an average of $4.64 \%$. The last row of Table 2 presents the utility gain or loss from revenue sharing in dollars. For an individual team owner, revenue sharing delivered an average annual utility gain of $\$ 12.7$ million. The present value of these gains or losses for the average team is $\$ 138.5$ million, discounted back to the 2002 season using a 3\% discount rate, or $\$ 146.5$ million using a $2 \%$ discount rate. ${ }^{25}$ Much of this net utility gain arises from the decrease in variance of team revenues that revenue sharing delivers, while decreasing the leptokurtic league revenue distribution (kurtosis) provided smaller net benefits. The net utility gain could have been even larger if the league local revenue distribution (before revenue sharing) did not become increasingly positively skewed over the seven seasons: from a Pearson skewness coefficient value of 0.935 in 2002 to 2.64 in 2009, falling back to 1.73 in the 2013 season.

23 Each team received approximately $\$ 18.6$ million in each of the 2002 through 2006 seasons, and $\$ 23.7$ million in each of the 2007 through 2013 seasons. https://sites.google.com/site/rodswebpages/codes. These amount to an average share of local revenue of $18.5 \%$ in 2002 , gradually declining to $11.8 \%$ in 2013 .

24 http://www.usinflationcalculator.com/.

25 The average real interest rate (reported by the World Bank) was 3\% for the U.S. over the 2002-2011 period. 
Figure 3 reports the effect of changes in $\theta$ on the present value of the utility increase over the period. The curve reflects the increasing importance of skewness to the final utility gain. From (15) it is apparent that the impact on utility is a positive function of $\theta$. Higher values of $\theta$ reflect higher values of risk aversion, but as is clear it does not mean that utility changes must be uniform. Our choice of $\theta=3$ is quite conservative in light of the shape of Figure 3, and suggests that the utility gains from revenue sharing could be much larger than we compute.

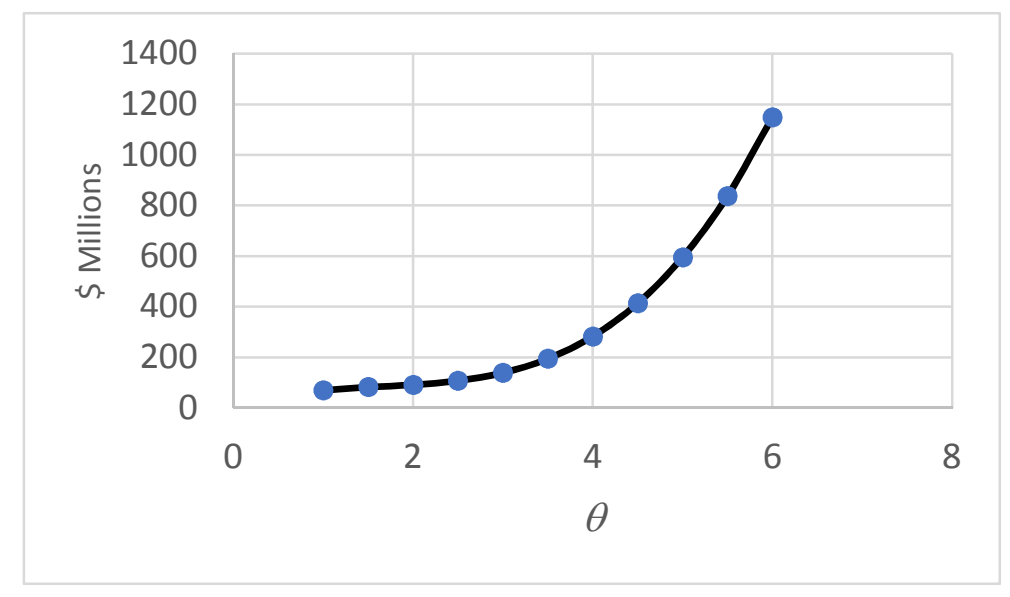

Figure 3. The prevent value in Dollars of the net utility gain with changes in $\theta$. (Discount rate $r=0.03$ and $\alpha=0.69$ and $\alpha=0.66$ as per text).

\section{Conclusions}

We have demonstrated significant utility gains to MLB from the straight pool revenue sharing system first adopted in the 2002 CBA. However, our measures of utility gain could be understated for several reasons. It may be that team owners are more risk-averse than we have assumed, implying that our values for $\theta$ are too small, but this seems unlikely. At the league level, stability of revenues could enhance the ability of a league commissioner to negotiate lucrative rights packages for television, internet, merchandising and so on. In the past, revenue sharing has also been a useful policy to prevent the formation of rival leagues by making the existing league attractive to cities that wish to join. At the team level, revenue sharing reduces the variance of local revenues after revenue sharing and hence reduces risk. This could have two beneficial effects for team owners. Lower risk can reduce the capital costs of new facilities for teams that wish to finance a portion or all of their new facilities. Local governments might be more willing to pick up a portion of the construction costs when they know that the team is on a stable financial footing and unlikely to leave for greener pastures once construction is finished. More importantly for team owners, low financial risk enhances the market value of the team when potential buyers are risk-averse. For many team owners, the financial rewards are the greatest when the team is sold.

Since revenue sharing costs little to implement, it would seem to be advantageous for a professional sports league to adopt it. In fact, further utility gains could be had by utilizing a progressive revenue tax. However, the wealthiest teams could oppose revenue sharing since the system penalizes on-field success and financial smarts. MLB has used a progressive competitive balance tax since the 1996 CBA. If their payrolls exceed the payroll threshold set in the most current CBA (\$195 million for the 2017 season) and if they are first-time offenders, teams pay a tax rate of $22.5 \%$ of the payroll overage. The tax rate increases to $30 \%$ for second-time offenders, $40 \%$ for third-time offenders and $50 \%$ for four or more offenses. It is estimated that the New York Yankees paid 
\$304 million in tax over the 2002-2016 seasons. ${ }^{26}$ Even though the tax system is progressive in some sense, the tax revenue is not redistributed to any of the MLB teams; hence the tax system lacks the redistributive effects of revenue sharing. Neither revenue sharing nor the competitive balance tax is an ideal system in a league utility sense.

Mirlees (1971) demonstrated that an optimal income tax system still features a progressive income tax rate, even after accounting for the negative work-incentive effects of the tax, although his criteria of welfare differed from ours in that he focused on utility from consumption for individual workers. It would be useful to explore whether the same result holds for the use of revenue sharing in a professional sports league using our measure of league welfare. However, it would necessitate specifying how the progressive revenue sharing tax affects the talent decisions of team owners; that is, stating what the function $R_{i}=R_{i}\left(\alpha, w_{i}\right)$ looks like. ${ }^{27}$ We leave that problem for future research.

Our paper is not without its shortcomings. Straight-pool revenue sharing has fairly predictable effects on team behavior that we chose to ignore in our static analysis. These include a decrease in player salaries, a redistribution of talent to large market teams, and a worsening of league parity. The ultimate effect on team profit is uncertain. Our concern is with the moments of the league local revenue distribution. Endogenizing these dynamic effects into a league model of local revenue with revenue sharing is a challenging task. We also abstract from the welfare effects of revenue sharing, and choose to only focus on the utility gains for the representative team owner. A more encompassing model of welfare would include the effects on team profits, and the effects on utility for consumers of MLB games arising from changes in consumer surplus and parity effects. This would require a general equilibrium model of league outcomes and consumer utility that we chose not to attempt. Finally, we consider only the effects of the straight-pool revenue sharing plan on the league local revenue distribution, ignoring the potential utility gains from the sharing of Central Fund revenues. Central Fund revenues do not arise from a tax on local revenues that arise from the profit-maximizing decisions of team owners. Instead they are typically treated in the literature as a fixed revenue that does not affect profit-maximizing decisions, although they obviously increase team profit. Nevertheless, we believe that the overlooking the distribution of Central Fund revenues is misplaced and worthy of future study.

Author Contributions: Authors equally contributed to the research and writing of the paper.

Conflicts of Interest: The authors declare no conflict of interest.

\section{References}

Asplund, Marcus. 2002. Risk-averse firms in oligopoly. International Journal of Industrial Organization 20: 995-1012. [CrossRef]

Bontemps, Tim. 2017. Why revenue sharing, one of the NBA's thorniest issues, demands a solution. The Washington Post, September 28, (Extracted on 6 February 2018).

Chiu, W. Henry. 2005. Skewness preference, risk aversion and the precedence changes on stochastic relations. Management Science 51: 1816-28. [CrossRef]

Choudhary, M. Ali, and Paul Levine. 2010. Risk-averse firms and employment dynamics. Oxford Economic Papers 3: 578-602. [CrossRef]

Dietl, Helmut, Markus Lang, and Stephan Werner. 2009. Social welfare in sports leagues with profit-maximizing and/or win-maximizing clubs. Southern Economic Journal 76: 375-96. [CrossRef]

Dixit, Avinash, and Victor Norman. 1986. Gains from trade without lump-sum compensation. Journal of International Economics 21: 111-22. [CrossRef]

26 Orinick (2017).

27 Marburger (1997) considers the effect of a progressive competitive balance tax on owner incentives and equilibrium outcomes, but does not consider a progressive revenue sharing tax. 
Easton, Stephen, and Duane Rockerbie. 2005. Revenue sharing, conjectures and scarce talent in a sports league model. Journal of Sports Economics 6: 359-78. [CrossRef]

Easton, Stephen, and Duane Rockerbie. 2010. The ebbs and flows of the game: Multiple equilibria in a sports league model. Journal of Sports Economics 11: 172-85.

Eeckhoudt, Louis, and Harris Schlesinger. 2013. Higher order risk attitudes. In Handbook of Insurance. Edited by Georges Dionne. New York: Springer, pp. 41-57.

Eeckhoudt, Louis, Christian Gollier, and Thierry Schneider. 1995. Risk-aversion, prudence and temperance: A unified approach. Economic Letters 48: 331-36. [CrossRef]

Fort, Rodney, and James Quirk. 1995. Cross-subsidization, incentives and team outcomes in professional team sports leagues. Journal of Economic Literature 33: 1265-99.

Fort, Rodney, and James Quirk. 2010a. Optimal competitive balance in single-game ticket sports leagues. Journal of Sports Economics 11: 587-601. [CrossRef]

Fort, Rodney, and James Quirk. 2010b. Optimal competitive balance in a season ticket league. Economic Inquiry 49: 464-73. [CrossRef]

Goldberg, Pinelopi Koujianou, and Nina Pavcnik. 2007. Distributional effects of globalization in developing countries. Journal of Economic Literature 45: 39-82. [CrossRef]

Herranz, Neus, Stefan Krasa, and Anne P. Villamil. 2015. Entrepreneurs, risk aversion and dynamic firms. Journal of Political Economy 123: 1133-76. [CrossRef]

Hill, James Richard, and Nicholas A. Jolly. 2015. Revenue sharing and player salaries in Major League Baseball. Journal of Sports Economics 18: 831-49. [CrossRef]

Kesenne, Stefan. 2000. Revenue sharing and competitive balance in professional team sports. Journal of Sports Economics 1: 56-65. [CrossRef]

Kesenne, Stefan. 2007. Revenue sharing and owner profits in professional sports models. Journal of Sports Economics 8: 519-29. [CrossRef]

Kesenne, Stefan. 2015. Revenue sharing and absolute league quality, talent investment and talent allocation. Scottish Journal of Political Economy 62: 51-58. [CrossRef]

Kimball, Miles. 1990. Precautionary saving in the small and in the large. Econometrica 58: 53-73. [CrossRef]

Knight, Frank. 1921. Risk Uncertainty and Profit. Boston: Houghton Mifflin Company, Reprinted in New York: Augustus M. Kelley, 1964.

Kraus, Alan, and Robert Litzenberger. 1976. Skewness preference and the valuation of risky assets. Journal of Finance 31: 1085-100.

Krautmann, Anthony. 2017. Risk-averse team owners and player's salaries in Major League Baseball. Journal of Sports Economics 18: 19-33. [CrossRef]

Kroll, Yoram, Haim Levy, and Harry Markowitz. 1984. Mean-variance versus direct utility maximization. Journal of Finance 39: 47-61. [CrossRef]

Leland, Hayne. 1972. Theory of the firm facing random demand. American Economic Review 62: $278-91$.

Levy, Haim, and Harry Markowitz. 1979. Approximating expected utility by a function of mean and variance. American Economic Review 69: 308-17.

Loistl, Otto. 1976. The erroneous approximation of expected utility by means of a Taylor series expansion. American Economic Review 66: 904-10.

Lucas, Robert. 1987. Models of Business Cycles. Oxford: Blackwell Publishers.

Major League Baseball. 2001. Updated Supplement to the Report of the Independent Members of the Commissioner's Blue Ribbon Panel on Baseball Economics. December. Available online: http:// roadsidephotos.sabr.org/baseball/BRpanelupd.doc (accessed on 2 August 2017).

Marburger, Daniel. 1997. Gate revenue sharing and luxury taxes in professional sports. Contemporary Economic Policy 15: 114-23. [CrossRef]

Markowitz, Harry. 1952. Portfolio selection. Journal of Finance 7: 77-91.

Maxcy, Joel. 2004. Motivating long-term employment contracts: Risk management in Major League Baseball. Managerial and Decision Economics 25: 109-20. [CrossRef]

Maxcy, Joel. 2009. Progressive revenue sharing in Major League Baseball: The effect on player transfers and talent distribution. Review of Industrial Organization 35: 275-97. [CrossRef]

Mehra, Rajnish, and Edward Prescott. 1985. The equity premium: A puzzle. Journal of Monetary Economics 15: 145-61. [CrossRef] 
Miller, Phillip. 2007. Revenue sharing in sports leagues: The effects on talent distribution and competitive balance. Journal of Sports Economics 8: 62-82. [CrossRef]

Mirlees, James. 1971. An exploration in the theory of optimal income taxation. Review of Economic Studies 38: 175-208. [CrossRef]

Neale, Walter. 1964. The peculiar economics of professional sports. Quarterly Journal of Economics 78: 1-14. [CrossRef]

Orinick, Steve. 2017. Competitive Balance Tax. Available online: http:/ /www.stevetheump.com/luxury_tax.htm (accessed on 2 August 2017).

Pulley, Lawrence. 1981. A general mean-variance approximation to expected utility for short holding periods. Journal of Financial and Quantitative Analysis 16: 361-73. [CrossRef]

Rockerbie, Duane. 2009. Free agent auctions and revenue sharing: A simple exposition. Journal of Sport Management 23: 87-98. [CrossRef]

Rockerbie, Duane. 2017. The invariance principle in baseball: New evidence. Applied Economics 50: $2613-21$. [CrossRef]

Rockerbie, Duane, and Stephen Easton. 2014. The Run to the Pennant: A Multiple Equilibria Approach to Professional Sports Leagues. New York: Springer.

Ross, J. Andrew. 2015. Joining the Clubs: The Business of the National Hockey League to 1945. Syracuse: Syracuse University Press.

Sandmo, Agnar. 1971. On the theory of the competitive firm under price uncertainty. American Economic Review 61: $65-73$.

Surdham, David. 2007. A tale of two gate-sharing plans: The National Football League and the National League, 1952-56. Southern Economic Journal 73: 931-46.

Szymanski, Stefan. 2004. Professional team sports are only a game: The Walrasian fixed-supply conjecture model, contest-Nash equilibrium, and the invariance principle. Journal of Sports Economics 5: 111-26. [CrossRef]

Tew, Bernard, Donald Reid, and Craig Witt. 1991. Opportunity cost of a mean-variance efficient choice. Financial Review 26: 31-44. [CrossRef]

Thomas, Jonathan, and Tim Worrall. 1988. Self-enforcing wage contracts. Review of Economic Studies 55: 541-53. [CrossRef]

Tompkins, D. 2000. The opportunity cost of E-V efficient portfolios. Academy of Accounting and Financial Studies Journal 4: 61-71.

Vrooman, John. 2009. Theory of the perfect game: Competitive balance in monopoly sports leagues. Review of Industrial Organization 34: 5-44. [CrossRef] 